\title{
An investigation of the effects of model structure on model performance to reduce discharge simulation uncertainty in two catchments
}

\author{
X. Zhang, G. Hörmann, and N. Fohrer \\ Fachabteilung Hydrologie und Wasserwirtschaft, Ökologie-Zentrum, Christian-Albrechts-Universität zu Kiel, Germany
}

Received: 17 January 2008 - Revised: 9 March 2008 - Accepted: 11 June 2008 - Published: 20 June 2008

\begin{abstract}
This paper investigates the variations of model performance caused by different model structures in both flow processes and model complexity level. Two case studies indicate that model efficiency is strongly dependent on model structure. The resulting substantial variation in both the model efficiency and the hydrographs from different model structures is used to estimate the structural uncertainty. The results help to select the most appropriate model adapted to local situations, which reveal great conformity with the actual hydrological patterns in both study basins.
\end{abstract}

\section{Introduction}

Uncertainty analysis is a valuable tool to test a model concept and to enhance confidence in streamflow simulation with hydrologic models. Model uncertainties generally stem from a variety of sources, like input data, formalization of model structure and parameter estimation, where it can affect the model predictions (Gupta et al., 2005). The system structure of hydrologic models is understood to be the algorithms and equations used to describe the natural flow systems that are themselves imperfectly known; the model uncertainty due to different structures can thus be of great significance in model predictions. However, compared to the abundance of literature on parameter and input data uncertainty, the topic of model structure and the associated uncertainty analysis has received relatively little attention in research. Only a few attempts are found in the literature to address this problem separately (Georgakakos et al., 2004; Lindenschmidt et al., 2007). This imbalance is partly due to the difficulty in assessing structural uncertainty or to separate it from other uncertainties during the calibration process (Beven and Binley,

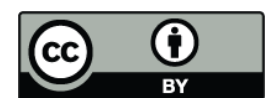

Correspondence to: X. Zhang (xzhang@hydrology.uni-kiel.de)
1992). This study investigates the structural uncertainty by examining the performance of models at various complexity levels programmed with the dynamic modelling language PCRaster (Wesseling et al., 1996). It was applied to two study basins - Kielstau in Germany and XitaoXi in China - which differ greatly in both geologic and hydrologic features. As all models are an approximation of the real world, the model structure should embody the essential hydrologic processes in the study region. The aims of this study are (i) to identify the impact of variation in model structure on discharge simulation; (ii) to reduce model uncertainty by selecting the most appropriate and efficient model structure for each catchment; and (iii) to examine if the selected model can capture the observed different features in the catchment.

\section{Study area}

Two different catchments - Kielstau and XitaoXi - are selected for this study, in order to find the best model structure for any given basins. Kielstau is a lowland watershed in Northern Germany, with an area of $51.49 \mathrm{~km}^{2}$. The maximum altitude difference within this area is $50 \mathrm{~m}$. Land use in Kielstau is predominantly agricultural (55.8\%) and grass (26.1\%). The main soil types are Cambisol and Luvisol, with dominating soil texture of sandy loam. XitaoXi, a $2271 \mathrm{~km}^{2}$ sized mountainous basin located in the semitropical zone in Southern China, is a sub-basin of the Taihu Lake. In the XitaoXi region, $63.4 \%$ of land use is forest and grass, $20 \%$ paddy rice land. Probably owing to the near surface ground water and a large fraction of wetland area in the Kielstau region, the hydrology of the Kielstau area is characterized by a special seasonal distribution of runoff/precipitation relation (Fig. 1 left). The monthly discharge values are not always in positive correlation with corresponding rainfall volumes. On the contrary, the distribution of river runoff in the XitaoXi catchment is mainly controlled by rainfall, which is quite

Published by Copernicus Publications on behalf of the European Geosciences Union. 

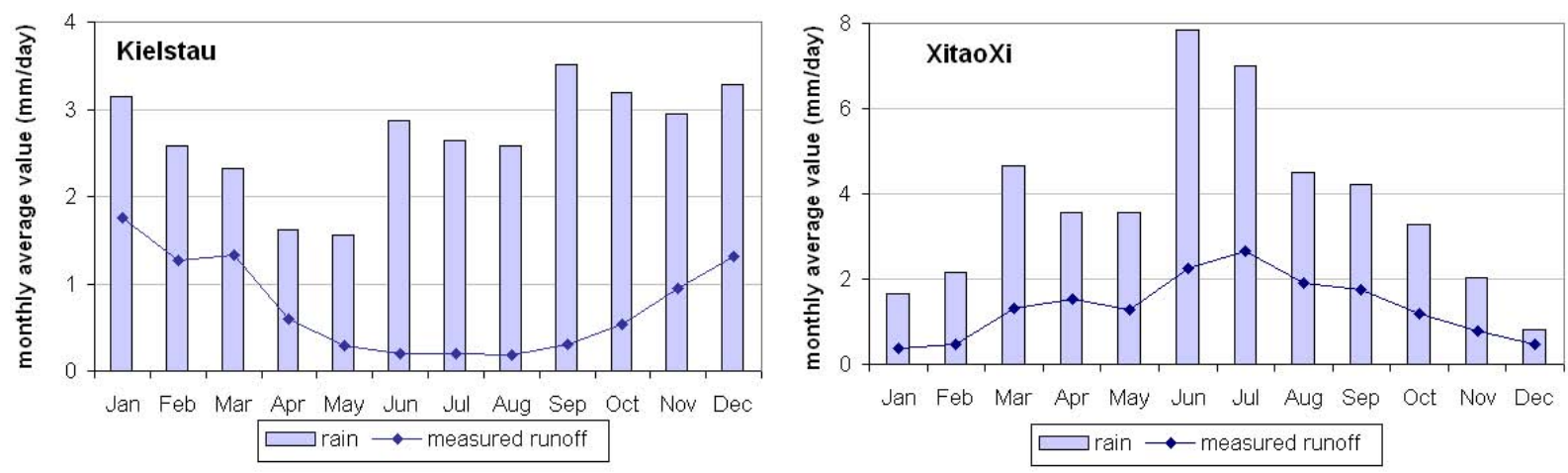

Fig. 1. Monthly rain and discharge mean value, based on data from 1990 to 1999 (for Kielstau), and from 1979 to 1988 (for XitaoXi).

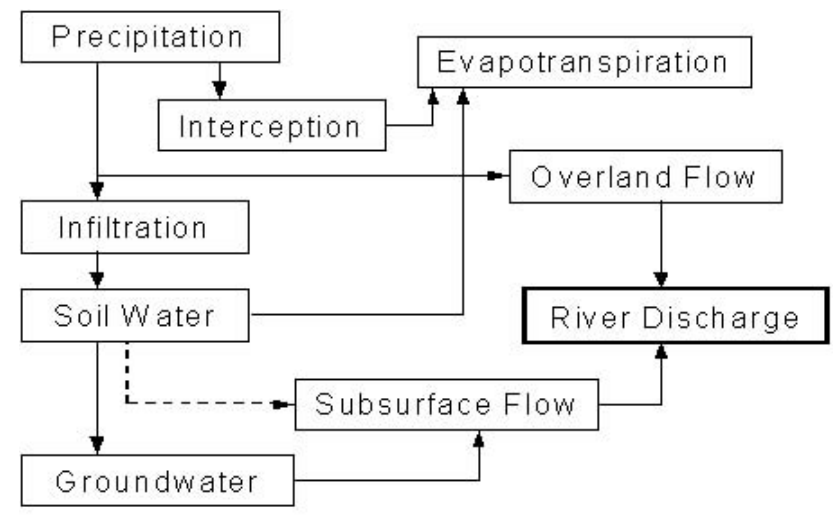

Fig. 2. Illustrations of the basic KIDS model structure "M".

common in mountainous regions (Fig. 1 right). All analyses in the following sections will be done in parallel for the two catchments.

\section{KIDS model and its derivatives}

The basic KIDS model concept was developed in Hörmann et al., 2007 for discharge simulation in the Kielstau catchment using PCRaster modelling language. It is simply structured as one-way hydrological flux without feedback. As indicated in Fig. 2, it is implemented with one lumped soil layer and one groundwater aquifer. The model is driven by meteorological input data like precipitation and evapotranspiration. The simulated hydrological fluxes include interception, infiltration, overland flow, and subsurface flow. River discharge is calculated with the kinematic wave function. More details about the KIDS model can be found in Hörmann et al., 2007 and Zhang et al., 2007.

We take the simple KIDS model concept as the basic model structure (abbreviated as "M") for both study basins. With this basic structure, other inputs like soils and land cover can be added as extended submodules to generate similar models. All derivative models form the KIDS model ensembles.

The model structures are developed with the following components: First, submodules are derived representing an extended process to be added to the basic model. We developed seven submodules for both Kielstau basin $(\mathrm{H}, \mathrm{S}, \mathrm{L}, \mathrm{T}$, G, D, W) and XitaoXi basin (P, E, X, G, L, T, R). A short description of all modules is summarized in Table 1. Secondly, the basic model " $\mathrm{M}$ " is combined with one or more modules from the first step to form a new model. All models are named with the characters of the submodules. The number of coupled modules indicates the model complexity. Finally, with the establishment of the models with different structures, the Nash-Sutcliffe (NS) index is used as model efficiency criterion to determine the most appropriate model structure for validation.

As the focus of this study is to evaluate the performance of different structures, all parameter values in the basic model "M" were kept unchanged for any model structure combinations. Owing to the different catchment scale and data availability, the model " $\mathrm{M}$ " in Kielstau basin is set up with a completely lumped distribution of precipitation and evaporation (calculated with Penman-Monteith method); while in XitaoXi catchment we used sub-basin distributed rainfall and evaporation (measured with the Chinese pan standard method).

\section{Results and discussion}

\subsection{Model structural uncertainty for calibration periods}

All created models were used to simulate river runoff for the calibration period from 1990 to 1994 for the Kielstau and from 1979 to 1983 for the XitaoXi. The resulting NS values are presented in Fig. 3 together with the corresponding model code and model complexity level. It was beyond the scope of this paper to list the complete set of model structure 
Table 1. Short description of all submodules in this study.

\begin{tabular}{|c|c|c|}
\hline Basin & $\begin{array}{l}\text { ID } \\
\mathrm{H}\end{array}$ & $\begin{array}{l}\text { Module description } \\
\text { Evapotranspiration (ET) calculated with Haude method (DVWK, 1996) }\end{array}$ \\
\hline \multirow{6}{*}{ Kielstau } & S & Upper soil layer integrated with spatial distribution of "Soil Water Content" referring to Sponagel et al., 2005 \\
\hline & $\mathrm{L}$ & Subsurface water flow from soil layer to river runoff \\
\hline & $\mathrm{T}$ & Spatial distributed ET adjusted with land use coefficients referring to Penman Monteith method (Allen et al., 1998) \\
\hline & $\mathrm{G}$ & Outflow threshold of groundwater flow to river discharge \\
\hline & $\mathrm{D}$ & Subsurface drainage \\
\hline & $\mathrm{W}$ & $\begin{array}{l}\text { Additional wetland fraction }(12 \%) \text { in the soil zone, which has unlimited water support for evaporation as its actual } \\
\text { ET equals the potential ET }\end{array}$ \\
\hline \multirow{7}{*}{ XitaoXi } & $\mathrm{P}$ & Lumped precipitation distribution and subbasin distributed ET \\
\hline & $\mathrm{E}$ & Lumped ET distribution and subbasin distributed precipitation \\
\hline & $\mathrm{X}$ & "Xinanjiang" runoff-producing process (Zhao and Liu, 1995) applied to the land use area of "forest and grass" \\
\hline & G & Outflow threshold of groundwater flow to river discharge \\
\hline & $\mathrm{L}$ & Subsurface water flow from soil layer to river runoff \\
\hline & $\mathrm{T}$ & Spatial distributed ET adjusted with land use coefficients referring to Gao, 2006 \\
\hline & $\mathrm{R}$ & Integration of two reservoirs in the upstream area referring to Jin and Gao, 2006 \\
\hline
\end{tabular}
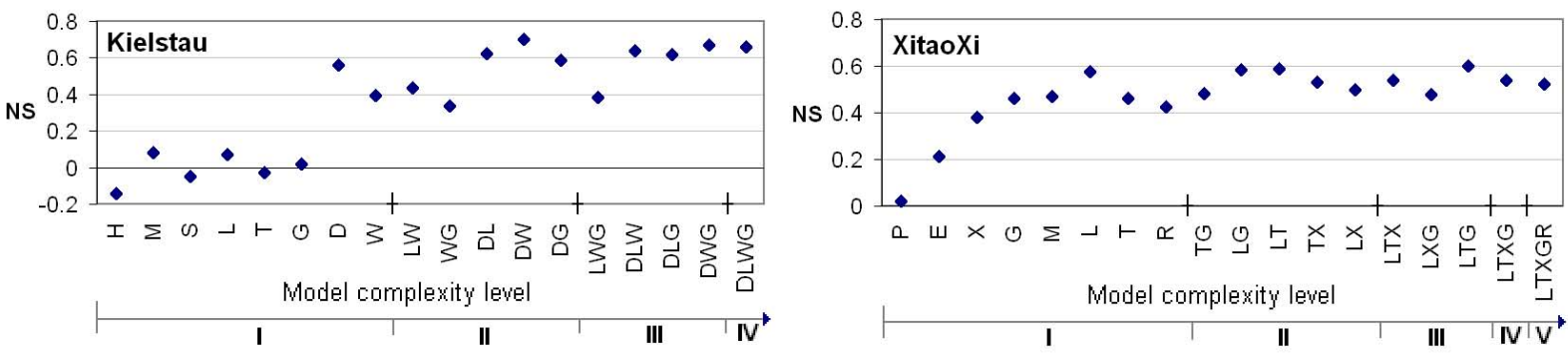

Fig. 3. The model efficiency (Nash-Sutcliffe index) of all model structures in relation with its complexity level for the Kielstau and the XitaoXi basin.

combinations. However, the models selected here are plausible alternatives for discharge simulation incorporating the main processes occurring in the basin. Not surprisingly, there is a high variation in model performances caused by the different model structures. This variation can be used as an estimate of structural uncertainty of the selected models. In both catchments, the NS value has a general tendency to increase with the model complexity level. The simpler models, like those coupled with only one module, perform relatively poor as compared with the more complex models.

For the Kielstau lowland basin the influence of drainage ("D") and wetland fraction ("W") improves model efficiency significantly. This is observed in the performance of its combination model as well: model "DW" outperforms all the selected models. Due to the low altitude variance, the lateral flow is not distinct in the Kielstau area. Instead, the wetland plays a more important role. For the mountainous XitaoXi basin, the most complex model "LTXGR" did not perform much better than simple models. It indicates that we could reduce the model complexity. Among all the tested models, the best performance is achieved by model "LTG", which is coupled with lateral flow process and groundwater outflow threshold, using spatial distribution of evaporation adjusted with land use coefficients. This indicates to a certain extent that the lateral flow is one of the dominating processes, and the influence from the groundwater is very limited.

Noted that different model structures can bring great variation in model efficiency, we plotted the simulated river discharges of all tested model structures along with the observations in Fig. 4. The grey areas of ensemble model simulations represent the structural uncertainty intervals around the observed discharge values. It shows that the simulations embrace the observed data most of time. The variation produced by different model structures for Kielstau catchment is observed to be wider than that for XitaoXi catchment. To some extent this dispersion of ensemble flows indicates the magnitude of structural uncertainty. 

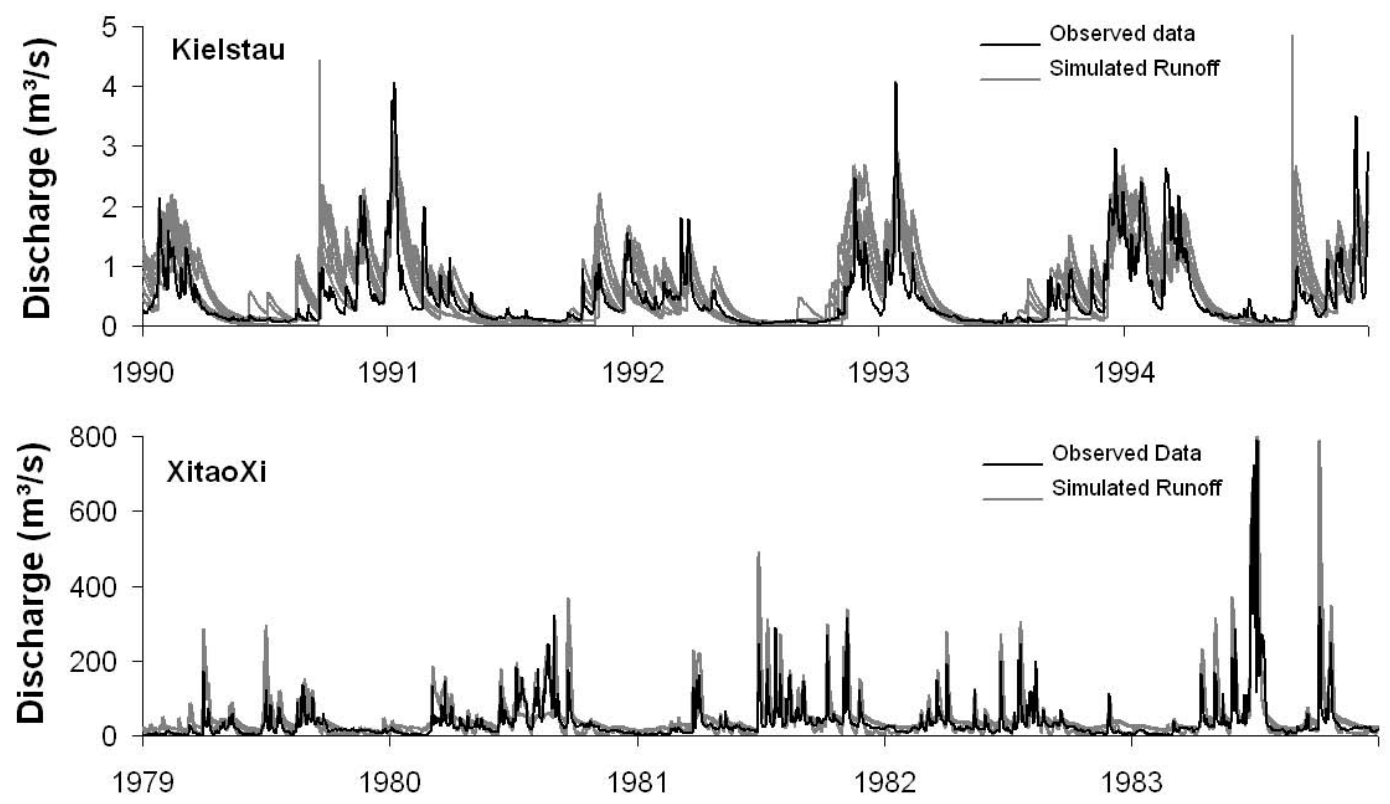

Fig. 4. Simulation results of different model structures for two study basins, with the shaded area showing the uncertainty intervals along with the measured discharge.
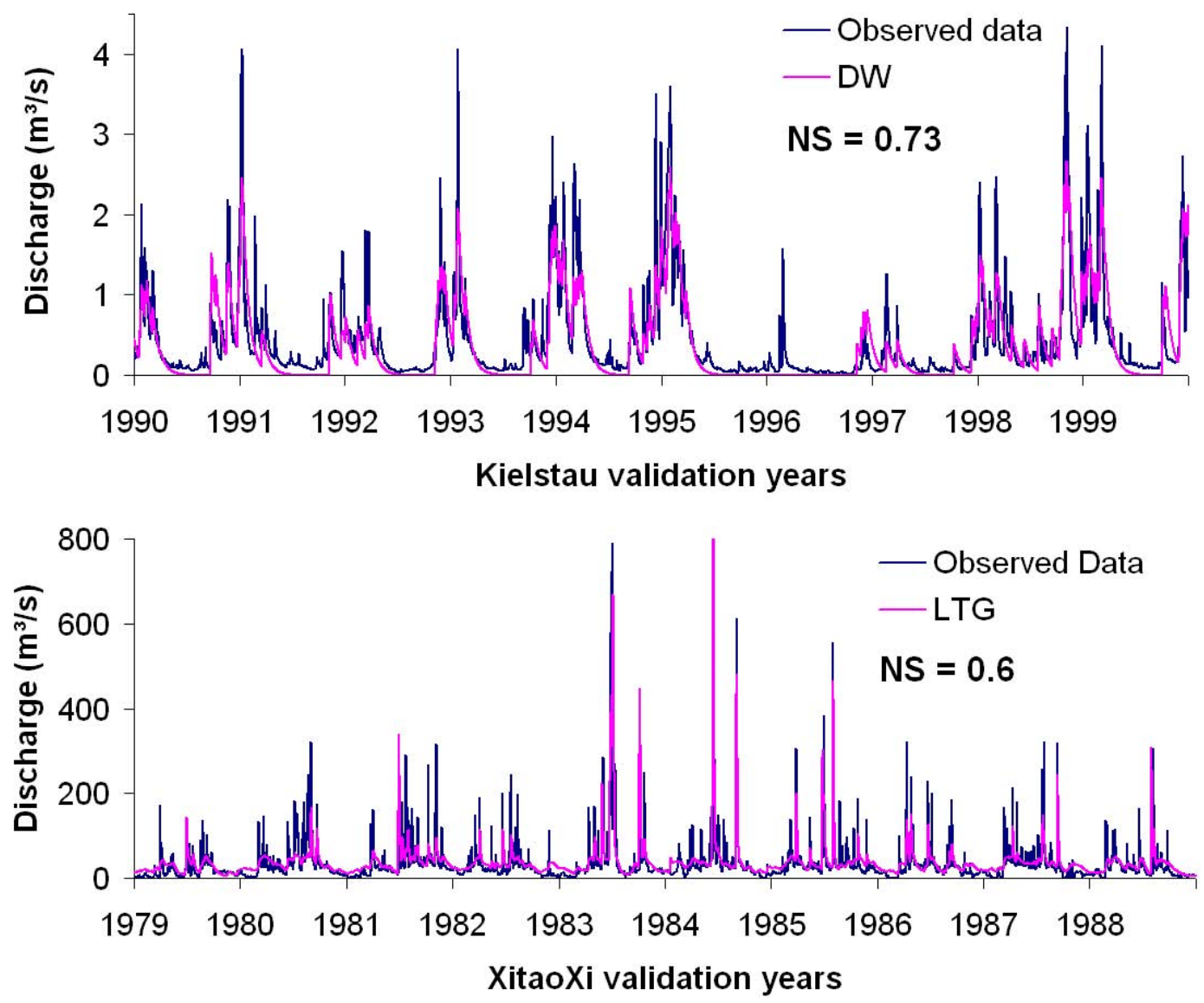

Fig. 5. Validated simulations of best-performing model structure compared to observed river discharge data. 


\subsection{Selecting the best performing model}

This result of uncertainty analysis is used to determine the most appropriate model structure for each basin. Model "DW" and model "LTG" are thus taken for model validation. As can be seen from the plots of observed and simulated hydrographs in Fig. 5, both selected models can reproduce the measured discharge reasonably well. The NS value for model "DW" of the Kielstau basin is 0.73 , and for model "LTG" of the XitaoXi basin it is 0.6. From the validation result, the discharge simulations can represent the observations in an acceptable range both in hydrographs and in measure of Nash-Sutcliffe coefficient. It ensured that the selected models could be considered to capture better the hydrological mechanisms in the catchment than other tested models. Moreover, it can help to identify pecularities of the hydrological processes in the study area.

\section{Conclusions}

Two case studies are conducted in this paper to investigate the effects of different model structures. The results show that model efficiency represented by the NS index is strongly dependent on model structure. The variation in model performances is taken as an estimation of structural uncertainty. Both case studies demonstrate that there is a trade-off between model complexity and simulation ability. The most complex model, which is a combination of all available process modules, does not produce the best simulation. The most appropriate model structure for each catchment is determined from the uncertainty analysis. The validated simulation with the best-performing model reaches a NS value of 0.73 for the Kielstau and 0.6 for the XitaoXi. The final outcome of this study is that for reducing model simulation uncertainty, it is important to explore different model structures and to adapt the models to the local situation. A further exploration of this uncertainty from model structure will be conducted with multi-criteria methods as an extended research in the near future.

Edited by: F. Portmann, K. Berkhoff, and M. Hunger Reviewed by: two anonymous referees and the editors

\section{References}

Allen, R. G., Pereira, L. S., Raes, D., and Smith, M.: Crop evapotranspiration - Guidelines for computing crop water requirements - FAO Irrigation and drainage paper 56, FAO Rome, M-56, ISBN: 92-5-104219-5, 1998.

Beven, K. and Binley, A.: The Future Of Distributed Models - Model Calibration And Uncertainty Prediction, Hydrol. Processes, 6(3), 279-298, 1992.

DVWK - Deutscher Verband für Wasserwirtschaft und Kulturbau e.V.: Ermittlung der Verdunstung von Land- und Wasserflächen. DVWK-Merkblätter zur Wasserwirtschaft, Heft 238, Bonn, p. 135, 1996.

Gao, J., Lu, G., Zhao, G., and Li, J.: Watershed data model: a case study of Xitiaoxi sub-waterhed, Taihu Basin. Journal of Lake Sciences, 18(3), 312-31, 2006.

Georgakakos, K. P., Seo, D.-J., Gupta, H., Schaake, J., and Butts, M. B.: Characterising streamflow simulation uncertainty through multimodel ensembles, J. Hydrol., 298(1-4), 222-241. 2004.

Gupta, H. V., Beven, K. J., and Wagener, T.: Model calibration and uncertainty estimation, in: Encyclopedia of hydrologic sciences, edited by: Anderson, M., Wiley, Chichester, 2005

Hörmann, G., Zhang, X., and Fohrer, N.: Comparison of a simple and a spatially distributed hydrologic model for the simulation of a lowland catchment in Northern Germany. Ecological Modelling, 209(1), 21-28, 2007.

Jin, X. and Gao, J.: Modeling of Human Activities Impacts to Hydrological Process - Based on Distributed Hydrological model. Master thesis, Nanjing Institute of Geography \& Limnology, Chinese Academy of Sciences, 2006.

Lindenschmidt, K. E., Fleischbein, K., and Baborowski, M.: Structural uncertainty in a river water quality modelling system. Ecological Modelling 204, 289-300, 2007.

Sponagel, H., Grottenthaler, W., and Hartmann, K.-J.: Bodenkundliche Kartieranleitung, 5. verbesserte und erweiterte Auflage, Hannover, p. 438, 2005.

Wesseling, C. G., Karssenberg, D. J., Burrough, P. A., and Van Deursen, W. P. A.: Integrated dynamic environmental models in GIS: The development of a Dynamic Modelling language. Transactions in GIS, 11, 4048, 1996.

Zhang, X., Hörmann, G., and Fohrer, N.: The Effects of Different Model Complexity on the Quality of Discharge Simulation for a Lowland Catchment in Northern Germany. Heft 20.07 'Einfluss von Bewirtschaftung und Klima auf Wasser- und Stoffhaushalt von Gewässern', Band 2, Forum für Hydrologie und Wasserbewirtschaftung, ISBN: 978-3-940173-04-1, 2007.

Zhao, R. and Liu, X.: The Xinanjiang Model, in: Computer models of watershed hydrology, edited by: Singh, V., Water Resources publications, Littleton, Colorado, 215-232, 1995. 